\title{
Conjunctival TGF-B Level in Primary Augmented Trabeculectomy
}

\author{
Guan Fook $\mathrm{Ng}^{1}$, Ishak Siti Raihan ${ }^{1}$, Yaakub Azhany ${ }^{1}$, Che Hussin Che Maraina ${ }^{2}$, \\ K. Gurusamy Banumathi ${ }^{3}$ and Ahmad Tajudin Liza-Sharmini ${ }^{*}, 1$
}

\author{
${ }^{I}$ Department of Ophthalmology, School of Medical Sciences, Health Campus, Universiti Sains Malaysia, 16150 Kota \\ Bharu, Kelantan, Malaysia \\ ${ }^{2}$ Department of Immunology, School of Medical Sciences, Health Campus, Universiti Sains Malaysia, 16150 Kota \\ Bharu, Kelantan, Malaysia \\ ${ }^{3}$ Hospital Pulau Pinang, Jalan Residensi, 10990 Georgetown, Pulau Pinang, Malaysia
}

\begin{abstract}
Purpose: To compare the levels of conjunctival transforming growth factor beta (TGF- $\beta$ ) between glaucoma and control patients and to determine conjunctival TGF- $\beta$ levels before and 3 months after augmented primary trabeculectomy.

Methods: Patients with primary open angle glaucoma (POAG) or primary angle closure glaucoma (PACG) admitted for mitomycin (MMC) augmented primary trabeculectomy due to failure in achieving target pressure after maximum medical therapy were selected. Age-matched non-glaucoma patients were controls. Impression cytology of the conjunctiva was obtained twice from glaucoma patients (1 week before augmented primary trabeculectomy and 3 months after surgery) and once from controls. Conjunctival cells were tagged with an anti-TGF- $\beta$ antibody and analyzed by flow cytometry.

Results: Eighteen patients (11 POAG and 7 PACG patients) and 18 age-matched control patients were included. Conjunctival TGF- $\beta$ levels were significantly different between glaucoma $(35.21 \% \pm 14.12 \%)$ and control patients $(14.96 \% \pm 6.34 \%)(\mathrm{p}=0.001)$. There was a significant reduction in conjunctival TGF- $\beta$ levels after augmented trabeculectomy $(23.0 \% \pm 13.8 \%)(\mathrm{p}<0.001)$. A significantly greater reduction in conjunctival TGF- $\beta$ levels $(61.6 \% \pm$ $17.9 \%$ ) was associated with complete success of trabeculectomy at 3 months $(83.3 \%)$ after surgical intervention ( $\mathrm{p}=$ $0.029)$.

Conclusion: The reduction of TGF- $\beta$ on the conjunctival post primary augmented trabeculectomy may suggest TGF- $\beta$ as potential predicting marker of short term trabeculectomy success. However, the result may be affected by site of impression, topical pressure lowering drugs and small sample size.
\end{abstract}

Keywords: Conjunctival TGFbeta, impression cytology, trabeculectomy.

\section{INTRODUCTION}

Trabeculectomy is a surgical procedure that provides an alternative pathway for aqueous drainage from the anterior chamber to the subconjunctival space by removing part of the trabecular meshwork and adjacent structures to reduce intraocular pressure in glaucoma [1]. Long-term outcome of trabeculectomy is determined by the wound healing response of the conjunctiva and the sclerostomy site. Unfortunately, the postoperative excessive wound healing process occur in many cases [2].

Nowadays, there is increasing interest in cytokines or growth factors that are involved in the wound healing cascade in the eye in order to promote the success rate of glaucoma filtering surgery $[3,4]$. Transforming growth factor beta (TGF- $\beta$ ) is identified as one of the important

*Address correspondence to this author at the Department of Ophthalmology, School of Medical Sciences, Health Campus, Universiti Sains Malaysia, 16150 Kota Bharu, Kelantan, Malaysia; Tel: +609 767 6353; Fax:+609 765 3370; E-mails: liza@usm.my; sharminiliz@live.com growth factors in wound healing after trabeculectomy. TGF$\beta$ is a multifunctional growth factor and belongs to a large superfamily of polypeptide molecules $[5,6]$. There are 3 isoforms of TGF- $\beta$ : TGF- $\beta 1$, TGF- $\beta 2$, and TGF- $\beta 3$. All 3 isoforms are found in the cornea, but TGF- $\beta 2$ is believed to be the predominant isotype $[5,6]$. TGF- $\beta 2$ is also the most potent growth factor that stimulates conjunctival fibroblast function [7] and is found predominantly in the vitreous, aqueous humor, and tears [8-10]. A significantly higher level of TGF- $\beta 2$ was found in the aqueous humor of glaucoma patients than that of non-glaucoma patients [11].

During augmented trabeculectomy, TGF- $\beta$ is released from platelets, neutrophils, macrophages, and fibroblasts at the site of injury. TGF- $\beta$ then stimulates formation of granulation tissue [12]. TGF- $\beta$ is also responsible for stimulating angiogenesis, fibroblast proliferation, myofibroblast differentiation, and matrix deposition [12].

To the best of our knowledge, no study has investigated the conjunctival levels of TGF- $\beta$ between glaucoma and nonglaucoma patients. The main objective of this study was to compare conjunctival TGF- $\beta$ levels between glaucoma 
patients and control patients and to determine the levels of conjunctival TGF- $\beta$ before and 3 months after augmented primary trabeculectomy. Finally, we aimed to associate conjunctival TGF- $\beta$ levels with the success of primary augmented trabeculectomy in Asian patients.

\section{MATERIAL AND METHODS}

This prospective cohort study was conducted between January 2010 and November 2011 and included glaucoma patients admitted for augmented primary trabeculectomy and age-matched non-glaucoma patients attending the eye clinic at the Hospital Universiti Sains Malaysia. This study received ethical approval from the research and ethical board of Universiti Sains Malaysia and was conducted in accordance with the Helsinki Declaration for Human Research.

\section{Patient Selection}

Primary open angle glaucoma (POAG) and primary angle closure glaucoma (PACG) patients scheduled to undergo augmented primary trabeculectomy between January and July 2011 were assigned to the study group. Glaucoma patients who had previous ocular surgery and those with systemic comorbidities that altered their immune status, such as autoimmune diseases, tuberculosis, or carcinomas, were excluded. Among the selected patients, those who developed complications, such as vitreous loss or suprachoroidal hemorrhage, during trabeculectomy surgery; experienced postoperative complications, such as severe uveitis or blebitis; or required needling within 3 months were excluded. The control group consisted of age-matched nonglaucoma patients who had an immature cataract of $\leq$ grade 2 based on the Lens Opacities Classification System (LOCS) III [13] and in whom accurate and reliable results of Humphrey visual field analysis and visualization of the optic nerve head could be obtained. Those with a strong family history of glaucoma, suspected diagnosis of glaucoma, history of ocular surgery, or history of long-term eye drop medication were considered as exclusion criteria. Long-term eye drop treatment was defined as eye drop medication including glaucoma medication for more than 6 years (72months).

\section{Impression Cytology}

Impression cytology was conducted with the patient lying in a supine position. Conjunctival cells were obtained using a hydrophilic membrane filter (Millipore GSWP01300, Italy). Topical anesthesia eye drops (Alcain-Alcon, Belgium) were instilled before the procedure. The membrane filter paper was cut into half, and the dull side of the filter paper was applied to the superior bulbar conjunctiva $2 \mathrm{~mm}$ from the superior limbus. The straight cutting edge of the filter paper was directed towards the limbus. Gentle pressure was applied using a cotton bud to ensure adherence of conjunctival cells to the paper. The paper was allowed to remain in contact with the eye for approximately 10 seconds and then peeled off with forceps. During the period of contact, the eyelid was held away from the paper, and extra care was taken to prevent tears from wetting the paper. The sample was discarded if there was evidence of wetting, and impression cytology was repeated.

Impression cytology was conducted twice for the study group: before primary augmented trabeculectomy (baseline) and 3 months after augmented trabeculectomy. Impression cytology was conducted only once for the control group. For performing impression cytology after augmented primary trabeculectomy, the filter paper was placed $2 \mathrm{~mm}$ from the superior limbus directly on the bleb. On average, 2 impression samples were collected during each procedure. The reflection of the glistening filter paper faded after the conjunctival epithelial cells adhered to the paper. Only adhered specimens that occupied more than half of the filter paper were selected and soaked immediately in $1.5 \mathrm{ml}$ of cold phosphate-buffered saline (PBS). The samples were analyzed in the immunology laboratory of the Universiti Sains Malaysia using flow cytometry (FACS Canto II, Becton Dickinson, United States).

Conjunctival cells on the filter paper were extracted by constant agitation for 30 minutes; subsequently, the filter paper was removed from the PBS solution, leaving the conjunctival cells in the PBS solution. The mixture was then centrifuged at $1600 \mathrm{rpm}$ for 5 minutes. The pellet precipitated at the bottom of the tube was isolated, and the remaining PBS solution was discarded. The pellet or precipitate from the PBS was divided into equal amounts (50 $\mu \mathrm{l}$ each) and placed into two 5-ml round-bottom test tubes. Fluorescein-conjugated anti-TGF- $\beta$ 1, 2, and 3 antibodies were added to the first tube, and an isotype of the control antibody was added to the second tube. Both tubes were then incubated in the dark for 30 minutes so that the anti-TGF- $\beta$ antibody could react with the TGF- $\beta$ on conjunctival cells. PBS was then added, and the tubes were centrifuged for 5 minutes. The pellet was isolated from the PBS solution, and the remaining PBS solution was discarded. The pellet was then resuspended for flow cytometry using fluorescence activated cell sorting (FACS) analysis. The result was expressed in percentage (\%) based on the cells detected by the TGF- $\beta$ marker and the total cells appeared in the computerize system of FACS II (FACS Canto II, Becton Dickinson, United States).

\section{Clinical Observations}

Glaucoma patients were followed-up at 1 week, 1 month, and 3 months postoperatively. Primary trabeculectomies were conducted by two glaucoma surgeons (LS and AY). Fornix based conjunctival peritomy was made. Rectangular partial thickness scleral flap was created. Surgical sponge was soaked with $0.4 \mathrm{mg} / \mathrm{ml}(0.04 \%)$ mitomycin C (MMC) and placed on the sclera slightly away from the scleral flap for 3 minutes duration. Sclerotomy was created using descemet punch, followed by surgical peripheral iridectomy. Scleral flap was closed using $10 / 0$ Nylon suture in interrupted manner (2-3sutures). Conjunctival was then closed using 9/0 Nylon. During each visit, patients were assessed for complications related to trabeculectomy, such as blebitis, endophthalmitis, or sign of failing surgery, including hypertony. At every visit, Goldmann applanation tonometry was conducted in the sitting position between 8:30 am and 12 noon. Humphrey visual field analysis (24-2) was conducted 3 months after trabeculectomy to detect any 
possible functional changes. Impression cytology was repeated for glaucoma patients 3 months after trabeculectomy.

Complete success of the trabeculectomy surgery was defined as an eye with an IOP of $\leq 21 \mathrm{mmHg}$ without use of pressure-lowering medication and non-progressive optic nerve damage $[14,15]$. Qualified success was defined as an eye with an IOP of $\leq 21 \mathrm{mmHg}$ with use of pressurelowering medication but without any evidence of progressive optic neuropathy $[14,15]$. Failed surgery was defined as an IOP of $>21 \mathrm{mmHg}$ with use of medication, progressive glaucomatous visual field loss combined with an increase of cupping of the optic disc regardless of the IOP, or the requirement of further pressure-lowering surgical procedures $[14,15]$.

All data was analyzed using Predictive Analytics Software (PASW) for Windows version 18.0. The Student ttest, Pearson Chi-Square, Fisher's exact test, and repeated measures ANOVA test were used to analyze the data. All pvalues of $<0.05$ were considered statistically significant.

\section{RESULTS}

Thirty-six glaucoma patients and controls were recruited. There was a statistically significant difference in the sex distribution between the study and control groups $(\mathrm{p}=0.034)$ (Table 1). There were significantly more females in the control group $(83.3 \%)$ than in the study group $(50 \%)$. Nine $(50 \%)$ patients were using 4 topical eye drops before augmented trabeculectomy. The mean duration of treatment before surgery was $51.9 \pm 55.7$ months. The main indication for augmented primary trabeculectomy was failure to achieve target pressure with maximum medical treatment.
The recruited POAG patients were older (age, $65.9 \pm$ 11.7 years) than the PACG patients (age, 61.7 \pm 8.2 years), but without statistical significance (Table 2). Among female patients, the prevalence of PACG was significantly higher than that of POAG $(p=0.016)$ (Table 2$)$. In addition, the prevalence of hypertension was higher among PACG patients than among POAG patients $(\mathrm{p}=0.016)$. There was no significant difference in the mean baseline IOP between POAG and PACG patients (Table 2). The duration of treatment before surgical intervention was greater for POAG patients than for PACG patients.

There was a statistically significant difference in the mean baseline percentage of TGF levels between the control and study groups $(\mathrm{p}=0.001)$. The mean percentage of TGF levels in the study group was more than twice the mean percentage of TGF levels in the control group. There was a statistically significant difference in TGF levels between POAG patients and the control group $(\mathrm{p}=0.016)$ and between PACG patients and the control group $(p<0.001)$ (Fig. 1).

In general, there was a statistically significant difference in conjunctival TGF- $\beta$ levels measured before and 3 months after trabeculectomy in the study group ( $p<0.001)$ (Fig. 2). Conjunctival TGF- $\beta$ levels measured before trabeculectomy showed a mean reduction of $22.98 \% \pm 13.81 \%$ at 3 months after trabeculectomy. The percentage of TGF- $\beta$ at baseline ( $\mathrm{p}$ $=0.211)$ and at 3 months after trabeculectomy $(p=0.688)$ was lower in POAG patients than in PACG patients (Fig. 2). Repeated measures ANOVA showed that there was no statistical difference between POAG and PACG patients when comparing TGF- $\beta$ levels before and after augmented trabeculectomy $(\mathrm{p}=0.337)$ (Fig. 3a).

Table 1. Comparison of demographic data between study group and control group.

\begin{tabular}{|c|c|c|c|c|}
\hline Demographic Characteristic & $\begin{array}{c}\text { Study Group } \\
\qquad \mathbf{N}=18\end{array}$ & $\begin{array}{c}\text { Control Group } \\
\mathbf{N}=18\end{array}$ & $\chi^{2}$ & p Value \\
\hline Mean age (mean, SD) & $64.3(10.4)$ & $62.1(10.3)$ & & $0.870^{\#}$ \\
\hline \multicolumn{5}{|l|}{$\operatorname{Sex}(\mathrm{n}, \%)$} \\
\hline Male & $9(50.0)$ & $3(16.7)$ & 4.500 & 0.034 \\
\hline Female & $9(50.0)$ & $15(83.3)$ & & \\
\hline \multicolumn{5}{|l|}{ Race (n,\%) } \\
\hline Malay & $16(88.9)$ & $11(77.8)$ & 3.704 & 0.054 \\
\hline Chinese & $2(11.1)$ & $7(22.2)$ & & \\
\hline \multicolumn{5}{|l|}{ Systemic disease (n,\%) } \\
\hline \multicolumn{5}{|l|}{ Hypertension } \\
\hline Yes & $9(50.0)$ & $6(33.3)$ & 1.029 & 0.310 \\
\hline No & $9(50.0)$ & $12(66.7)$ & & \\
\hline \multicolumn{5}{|l|}{ Hyperlipidemia } \\
\hline Yes & $3(16.7)$ & 0 & & $0.229 *$ \\
\hline No & $15(83.3)$ & $18(100)$ & & \\
\hline \multicolumn{5}{|l|}{ Diabetes Mellitus } \\
\hline Yes & $4(22.2)$ & 0 & & $0.104 *$ \\
\hline No & $14(77.8)$ & $18(100)$ & & \\
\hline
\end{tabular}

$\mathrm{p}<0.05$ is considered statistical significant based on Pearson Chi-Square, \# student t-test, ${ }^{*}$ Fisher's Exact Test. 
Table 2. Comparison of demographic data and management between POAG and PACG patients.

\begin{tabular}{|c|c|c|c|c|}
\hline Demographic and Clinical Characteristic & $\begin{array}{c}\text { POAG } \\
\mathbf{N}=11\end{array}$ & $\begin{array}{c}\text { PACG } \\
\mathbf{N}=7\end{array}$ & $\chi^{2}$ & p Value \\
\hline Mean age (mean, SD) & $65.9(11.7)$ & $61.7(8.2)$ & & $0.597^{\sharp}$ \\
\hline \multicolumn{5}{|l|}{$\operatorname{Sex}(n, \%)$} \\
\hline Male & $8(72.7)$ & $1(14.3)$ & 5.844 & 0.016 \\
\hline Female & $3(27.3)$ & $6(85.7)$ & & \\
\hline \multicolumn{5}{|l|}{ Race $(n, \%)$} \\
\hline Malay & $10(90.9)$ & $6(85.7)$ & 0.117 & 0.732 \\
\hline Chinese & $1(9.1)$ & $1(14.3)$ & & \\
\hline \multicolumn{5}{|l|}{ Medical disease $(\mathrm{n}, \%)$} \\
\hline \multicolumn{5}{|l|}{ Hypertension } \\
\hline Yes & $8(72.7)$ & $6(85.7)$ & 5.844 & 0.016 \\
\hline No & $3(27.3)$ & $1(14.3)$ & & \\
\hline \multicolumn{5}{|l|}{ Hyperlipidemia } \\
\hline Yes & $2(18.2)$ & $1(14.3)$ & 0.047 & 0.829 \\
\hline No & $9(81.8)$ & $6(85.7)$ & & \\
\hline \multicolumn{5}{|l|}{ Diabetes Mellitus } \\
\hline Yes & $4(36.4)$ & 0 & & $0.119 *$ \\
\hline No & $7(63.6)$ & $7(100)$ & & \\
\hline Baseline IOP (mean, SD) & $65.9(11.7)$ & $61.7(8.2)$ & & $0.597^{\sharp}$ \\
\hline \multicolumn{5}{|l|}{ VA $(n, \%)$} \\
\hline $6 / 6-6 / 9$ & $3(27.3)$ & 0 & & $0.622 *$ \\
\hline $6 / 12-6 / 18$ & $2(18.2)$ & $3(42.9)$ & & \\
\hline $6 / 24-6 / 36$ & $3(27.3)$ & $2(28.6)$ & & \\
\hline CF-HM & $2(18.2)$ & $2(28.6)$ & & \\
\hline PL & $1(9.1)$ & 0 & & \\
\hline \multicolumn{5}{|l|}{$\operatorname{VCDR}(\mathrm{n}, \%)$} \\
\hline $0.7-0.9$ & 11(100) & $7(100)$ & & 1.000 \\
\hline MD (mean, SD) & $-22.01(11.04)$ & $-26.77(10.13)$ & & $0.467^{\sharp}$ \\
\hline PSD (mean, SD) & $7.88(3.82)$ & $4.83(1.53)$ & & $0.164^{\#}$ \\
\hline \multicolumn{5}{|l|}{ Number of Topical drops (n,\%) } \\
\hline Double & $1(9.1)$ & 0 & & 0.778 \\
\hline Triple & $4(36.4)$ & $4(57.1)$ & & \\
\hline Quadruple & $6(54.5)$ & $3(42.9)$ & & \\
\hline Duration of treatment in months (mean, SD) & $60.09(64.24)$ & $39.14(40.13)$ & & $0.818^{\#}$ \\
\hline \multicolumn{5}{|l|}{ Reason for trabeculectomy } \\
\hline Failed to achieve target pressure & $7(63.6)$ & $7(100)$ & & $0.119 *$ \\
\hline Progression of glaucoma & $4(36.4)$ & 0 & & \\
\hline
\end{tabular}

$\mathrm{p}<0.05$ is considered statistical significant based on Pearson Chi-Square, \# student t-test and* Fisher's Exact Test. 


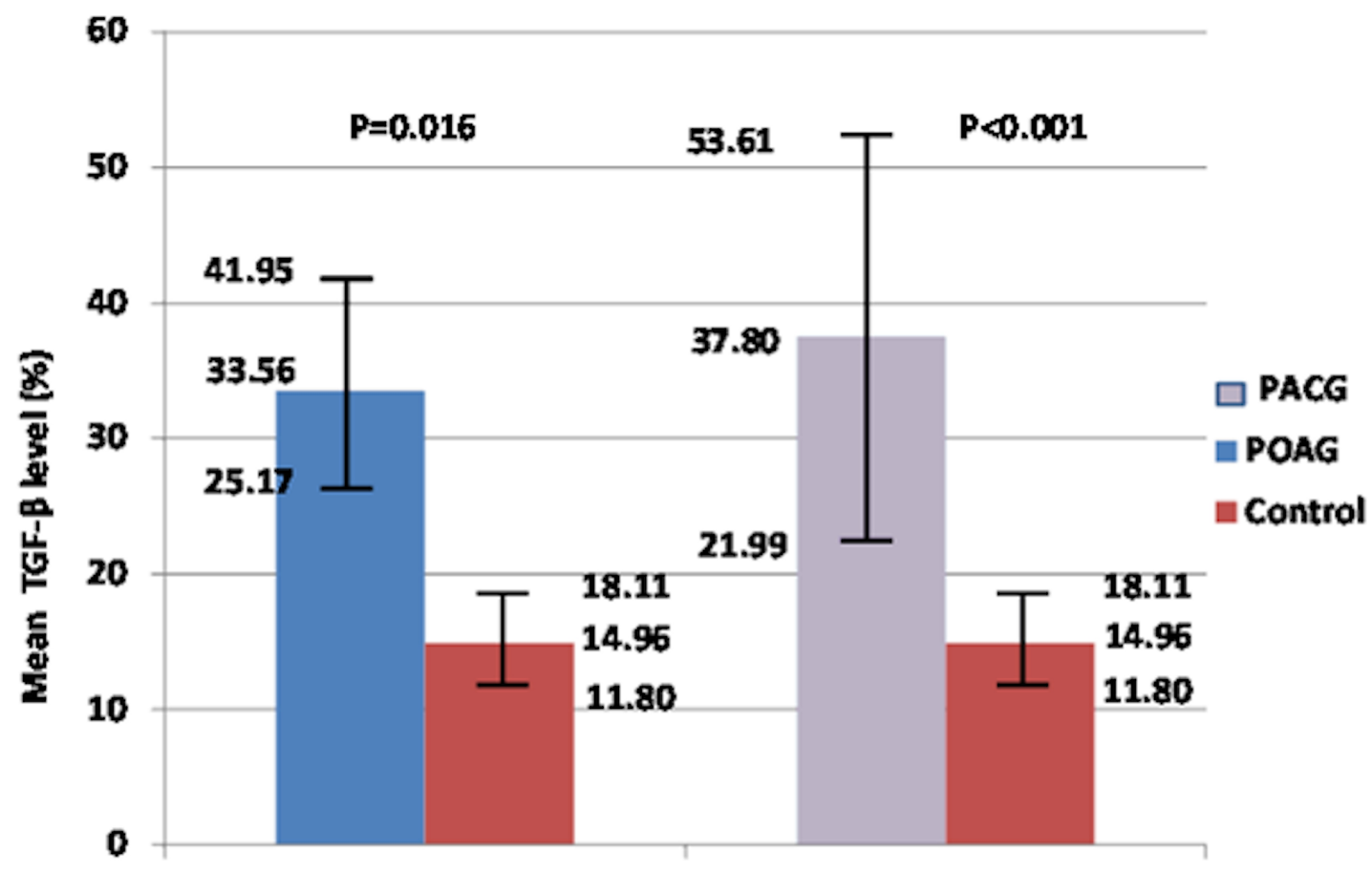

p< 0.05 is considered statistical significant based on student t-test

Fig. (1). Comparison of TGF- $\beta$ level on the conjunctiva between control and study group.

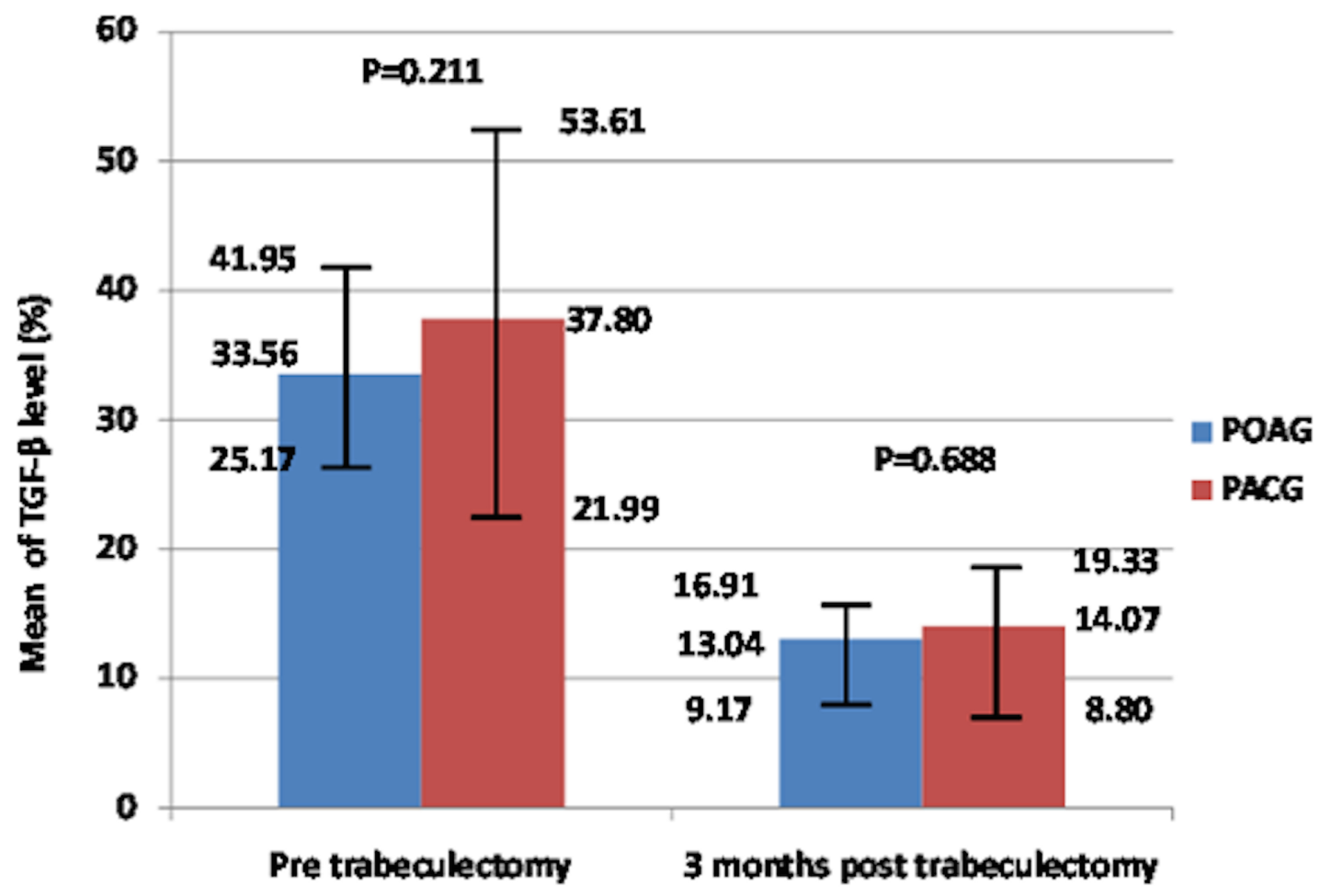

$p<0.05$ is considered statistical significant based on student t-test

Fig. (2). Comparison on the conjunctival TGF- $\beta$ level at pre and 3 months post augmented trabeculectomy between POAG and PACG. 
All PACG patients achieved more than $40 \%$ reduction in conjunctival TGF- $\beta$ levels at 3 months after augmented primary trabeculectomy. However, only $72.7 \%$ of POAG patients were able to achieve a greater than $40 \%$ reduction (Fig. 3b). Eight POAG patients (72.7\%) achieved complete success at 3 months after augmented primary trabeculectomy. Complete success was achieved in all PACG patients ( 7 patients) at 3 months after augmented primary trabeculectomy. However, there was no statistically significant association between conjunctival TGF- $\beta$ level and the success rate of augmented primary trabeculectomy in POAG and PACG patients $(\mathrm{p}=0.245)$.

Surprisingly, there was a significantly greater reduction in conjunctival TGF- $\beta$ levels in patients who achieved complete trabeculectomy success $(\mathrm{p}=0.029)$. The mean reduction in conjunctival TGF- $\beta$ levels was $61.6 \% \pm 17.9 \%$ in complete success surgeries but only $42.0 \% \pm 42.1 \%$ in qualified success surgeries.

\section{DISCUSSION}

The success of trabeculectomy surgery is mainly based on the healing process at the interface between the conjunctival and sclerotomy site that allows access for aqueous outflow. The conjunctiva scarring in trabeculectomy is thought to be greatly influenced by the aqueous passage of growth factors, such as TGF- $\beta$, through the surgical site. ${ }^{8}$ Thus, TGF- $\beta$ level is a potential predictor of trabeculectomy success. Previously, TGF- $\beta$ was detected through aspiration from the aqueous humor or using immunohistochemistry techniques to examine conjunctival biopsy specimens [8-10, 16]. To the best of our knowledge, this is the first study to assess TGF- $\beta$ levels using conjunctiva impression cytology with flow cytometry. Impression cytology is a non-invasive, relatively easy technique for obtaining conjunctival tissue for further laboratory evaluation.

The mean conjunctival TGF- $\beta$ levels were significantly higher in glaucoma patients than in age-matched controls. However, although inconclusive, it was found that long-term treatment with topical pressure-lowering drugs causes excessive scarring and failure of trabeculectomy surgery [16]. Recently, the long-term use of topical pressurelowering medications was found to enhance proliferation of human Tenon's capsule fibroblasts (HTF) and abnormal expression of TGF- $\beta$ and matrix metalloproteinases (MMPs)[16]. Long duration of treatment with multiple topical pressure-lowering drugs, particularly prostaglandin analogs, is perhaps responsible for the higher levels of conjunctival TGF- $\beta$ in our study. A significant elevation in TGF- $\beta$ was found in conjunctival biopsy specimens obtained from patients treated with multiple topical pressure-lowering drugs in a study conducted by Leng et al. [16]. Leng et al. also found that expression of TGF- $\beta 2$ was significantly higher in POAG patients than in controls [16]. The duration of treatment was also found to contribute to the postulated subclinical inflammation induced by these drugs [17].

The sampling technique used for obtaining conjunctival epithelial cells from impression cytology varies in different studies [18, 19]. This process may influence the cell yield because of histological differences in the distribution of goblet cells and other cells [18]. However, since our aim was to detect conjunctival TGF- $\beta$ levels and not to identify cells histologically, this is likely not a crucial issue. The samples were obtained from the superior and superotemporal bulbar conjunctiva, at the site of the trabeculectomy bleb that we believe to be representative of the actual site of scarring after trabeculectomy. We postulated that other inflammatory cells, including cytokines from other parts of the conjunctiva, migrated to the site of surgical injury as part of the inflammatory reaction.

We studied TGF- $\beta$ levels without exclusively looking into the individual isoforms of TGF- $\beta$, even though TGF- $\beta 2$ was found to be the most potent growth factor that stimulates conjunctiva fibroblast function [7-9]. TGF- $\beta 2$ also potentially influences ciliary muscle contraction of outflow facility and obstructs aqueous humor outflow through the trabecular meshwork [20]. Because of the potentially important role of TGF- $\beta 2$, a recombinant human monoclonal antibody to human TGF- $\beta 2$ was invented and is known as CAT-152 (Cambridge Antibody Technology, Cambridge UK). However, no significant effect on fibrogenesis was observed between patients treated with CAT-152 and those treated with placebo in a phase 3 study [21]. This finding suggests that other isoforms play important roles in fibrogenesis or the complex cascade of events involved in glaucoma [21]. Although the low dose of CAT-152 may also be responsible. The detection of all isoforms will perhaps provide a clearer picture of the role of TGF- $\beta$ in the scarring process after trabeculectomy. Moreover, all TGF- $\beta$ isoforms are expressed on the conjunctiva [7].

The passage of aqueous humor through the bleb is believed to bring along the inflammatory mediators and cytokines after surgery [22]. Cytokines in the aqueous humor, such as TGF- $\beta$, are believed to be responsible for the scarring effect [8]. Unfortunately, in our study, we did not measure aqueous levels of TGF- $\beta$. The summation of TGF- $\beta$ levels on the conjunctiva and in aqueous humor may provide more accurate information on the scarring activity. We found that conjunctival TGF- $\beta$ levels were higher in our small sample of PACG patients than in POAG patients. Since all of our recruited PACG patients had a history of acute presentation of angle closure (APAC), the acute inflammatory processes may contribute to the finding [23]. Because TGF- $\beta$ plays important roles in regulating inflammation, there may be evidence of chronic subclinical inflammation in PACG patients even after the acute attack has subsided. On the other hand, higher TGF- $\beta$ level could also be attributed to the summation effect of acute inflammation and subsequent long-term treatment with topical pressure-lowering drugs. Moreover, TGF- $\beta$ levels may also be influenced by gender, as males were found to have higher TGF- $\beta$ serum levels [24]. However, the small sample size of PACG patients could also be a source of bias in this study. Therefore, a larger sample size is necessary to draw a conclusive observation between the type of glaucoma and TGF- $\beta$ level. Furthermore, there are other factors that may affect these two types of glaucoma.

Trabeculectomy success was found to be lower in Asian populations than in Caucasians [25-27]. To the best of our knowledge, there was no study that has assessed possible associations between conjunctival TGF- $\beta$ level and trabeculectomy success rate. Theoretically, lower TGF- $\beta$ 


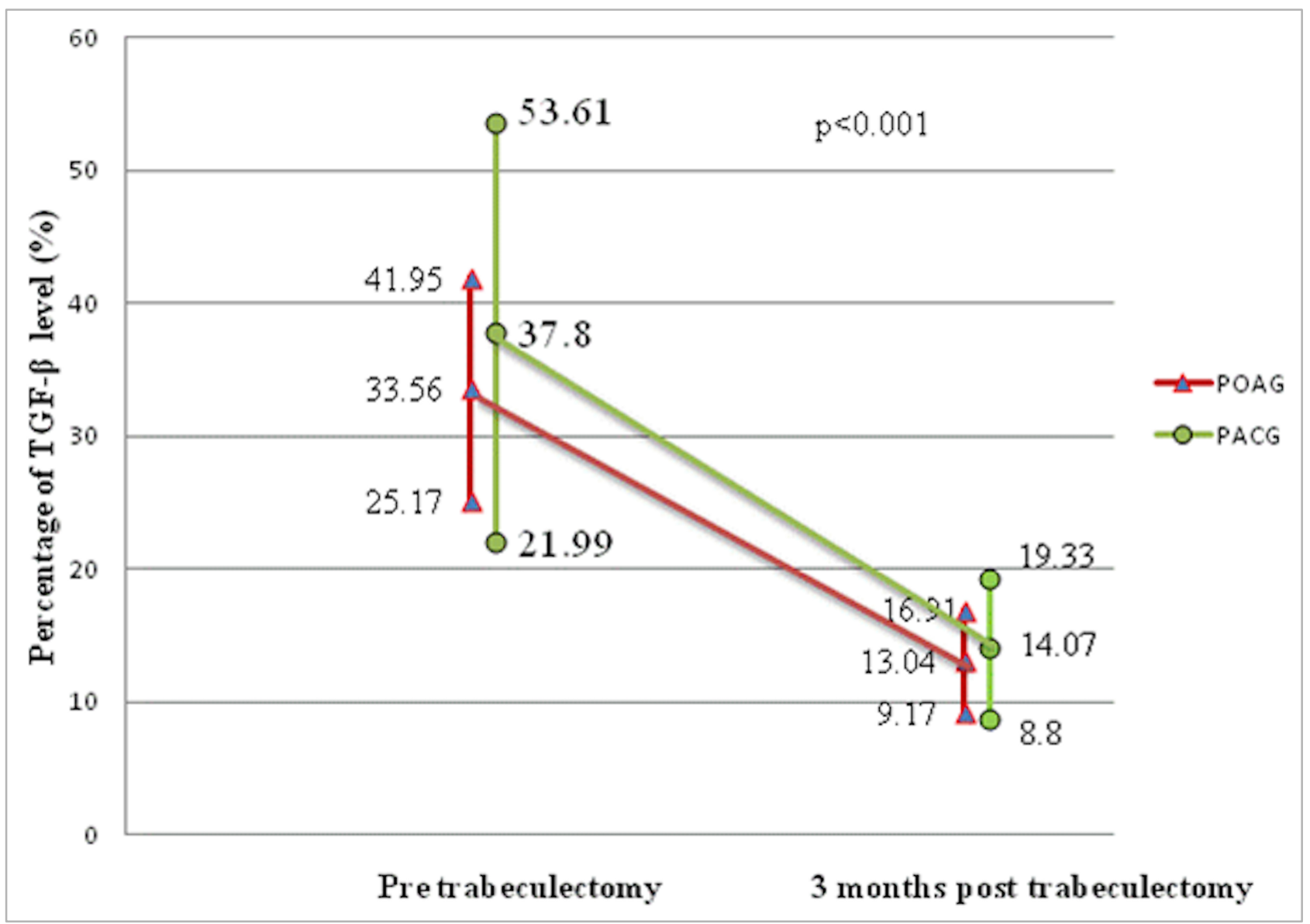

Fig. (3a). Comparison of the pattern of conjunctival TGF- $\beta$ level at pre and 3 months post augmented trabeculectomy between POAG and PACG.

levels increase the success rate of trabeculectomy surgery. Our result indicates that a greater reduction in TGF- $\beta$ is associated with a higher success rate of augmented primary trabeculectomy at 3 months after surgery. In addition, the reduction in TGF- $\beta$ levels from baseline was greater in those with complete success than in those with qualified success. Lower reduction of TGF- $\beta$ in those patients who were categorized as 'failure trabeculectomy' may be due to the topical pressure lowering drugs. Topical pressure lowering drugs were restarted in cases that the trabeculectomies were failing or failed. However, there was no significant association between trabeculectomy success and TGF- $\beta$ level. Our short observation of trabeculectomy success indicates that some patients show signs of early failure.

The reduction in TGF- $\beta$ level was partly due to the suppression of inflammatory processes caused by ongoing, intensive topical steroid instillation. Ideally, impression cytology should be obtained again at 1 year after trabeculectomy, and trabeculectomy success should also be evaluated at that time. Mitomycin C (MMC) was used for all patients and could also be responsible for reducing the TGF$\beta$ levels. There was evidence of fewer inflammatory cells at the operated site after MMC treatment due to suppression of angiogenesis at the wound site [28]. Obtaining the impression cytology from the inferior half of the conjunctival is another option but this will not represent the actual changes post augmented trabeculectomy. A group of patients who have undergone non-augmented primary trabeculectomy is ideal to investigate the effects of MMC on TGF- $\beta$ levels. However, due to the poor success rate of trabeculectomy in our patients, especially those with PACG, it was considered unethical to exclude MMC from our management.

Long exposure to multiple topical pressure-lowering drugs was the main confounder in this study. Perhaps, the comparison is best made between newly diagnosed glaucoma patient before initiation of medical treatment and non-glaucoma patients (control). There was significant reduction in conjunctival TGF- $\beta$ levels 3 months after augmented primary trabeculectomy, but this finding is confounded by immunosuppressive treatment and reinitiation of topical pressure-lowering drugs. Thus, the role of TGF- $\beta$ in the success rate of trabeculectomy is inconclusive. A larger sample size with longer follow-up duration is required in future studies. 


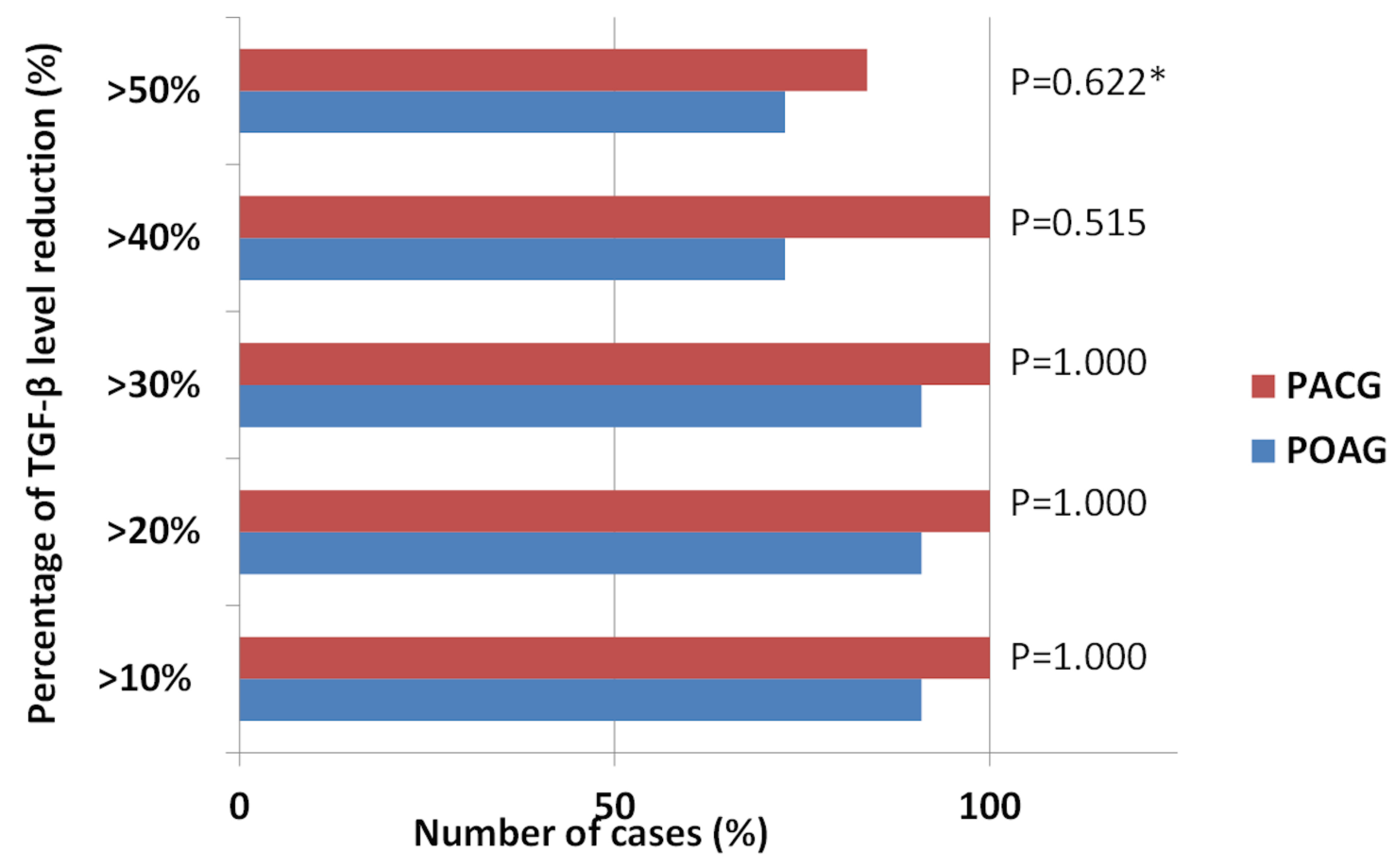

\section{$\mathrm{p}<0.05$ is considered statistical significant based on Fisher's Exact Test ${ }^{*} \mathrm{P}<0.05$ is considered statistical significant based on Pearson Chi-Square}

Fig. (3b). Comparison of the percentage of conjunctiva TGF- $\beta$ level reduction between POAG and PACG patients at different cut off points.

\section{CONFLICT OF INTEREST}

The authors confirm that this article content has no conflict of interest.

\section{ACKNOWLEDGEMENTS}

We would like to record our sincere appreciation to Mr. Jamaruddin bin Mat Asan, Senior technician, Department of Immunology, Universiti Sains Malaysia for the technical support and invaluable advice with the flow cytometer. This study was partially funded by USM short term grant 304/PPSP/61311074.

\section{REFERENCES}

[1] Cairns JE. Trabeculectomy: preliminary report of a new method. Am J Ophthalmol 1968; 673-9.

[2] Skuta GL, Parrish RK II. Wound healing in glaucoma filtering surgery. Surv Ophtahlmol 1987; 32: 149-70.

[3] Dilani S, Peng TK, Anthony JK, et al. Francesca Cordeiro. Human antitransforming growth factor monoclonal antibody - a new modulator of wound healing in trabeculectomy. Ophthalmology 2002; 109: 427-31.

[4] Cordeiro MF, Siriwardena D, Chang L, Khaw PT. Wound healing modulation after glaucoma surgery. Curr Opin Ophthalmology 2000; 11: 121-6.

[5] Roberts AB, Sporn MB. The transforming growth factor. In: Sporn $\mathrm{MB}$, Roberts $\mathrm{AB}$, Eds. Growth Factors and their Receptors. Handbook of Experimental Pharmacology. Heidelberg: SpringerVerlag 1990; pp. 419-72.

[6] Nishida K, Sotozono C, Adachi W, Yamamoto S, Yokoi N, Kinoshita S. Transforming growth factor beta 1, -beta 2 and -beta 3 mRNA expression in human cornea. Curr Eye Res 1995; 14: 23541.
[7] Cordeiro, MF, Gay, JA, Khaw, PT. Human anti-transforming growth factor-beta2 antibody: a new glaucoma anti-scarring agent. Invest Ophthalmol Vis Sci 1999; 40: 2225-34.

[8] Jampel HD, Roche N, Stark WJ, Roberts AB. Transforming growth factor-beta in human aqueous humor. Curr Eye Res 1990; 9: 963-9.

[9] Connor TB, Roberts AB, Sporn MB, et al. Correlation of fibrosis and transforming growth factor beta type 2 levels in the eye. J Clin Invest 1989; 83: 1661-6.

[10] Kokawa N, Sotozono C, Nishida K, Kinoshita S. High total TGF$\beta 2$ levels in normal human tears. Curr Eye Res 1996; 15: 341-342.

[11] Tripathi RC, Li J, Chan WF, Tripathi BJ. Aqueous humor in glaucomatous eyes contains an increased level of TGF-beta 2. Exp Eye Res 1994; 59: 723-7.

[12] Roberts AB, Sporn MB. Transforming growth factor- $\beta$. In: Clark RAF, Ed. The molecular and cellular biology of wound repair. $2^{\text {nd }}$ ed. New York: Plenum 1996; pp. 275-308.

[13] Chylack LT, Wolfe JK, Singer DM, et al. The Lens Opacities Classification System III. Arch Ophthalmol 1993; 111: 831-6.

[14] Holger M, Birgit R, Gunter KK. Risk factors for failures of trabeculectomies performed without antimetabolites. $\mathrm{Br} \quad \mathrm{J}$ Ophthalmol 1999; 83: 814-21.

[15] Araujo SV, Spaeth GL, Roth SM, Starita RJ. A ten year follow up on a prespective, randomized trial of postoperative corticosteroids after trabeculectomy. Ophthalmology 1995; 102: 1753-9.

[16] Leng F, Liu P, Li H, Zhang J. Long-term topical antiglaucoma medications cause enhanced Tenon's capsule fibroblast proliferation and abnormal TGF- $\beta$ and MMP expressions: potential effects on glaucoma filtering surgery. Curr Eye Res 2011; 36(4): 301-9.

[17] Broadway DC, Grierson I, Hitchings R. Adverse effects of topical antiglaucomatous medications on the conjunctiva. Br J Ophthalmol 1993; 77: 590-6.

[18] Ihan A, Cvenkel B. Conjunctival epithelium expression of HLADSR in glaucoma patients and its influence on the outcome of filtration surgery. Br J Ophthalmol 2000; 84: 648-50.

[19] Cheong Min Tet. A study on the expression of HLA-DR on conjunctival epithelial cells in patients treated with topical Latanoprost as adjunctive therapy and its association with 
protanoid (FP) receptor polymorphisms. M. Med. Thesis, 2007. Universiti Sains Malaysia

[20] Lutjen-Drecoll E. Morphological changes in glaucomatous eyes and the role of TGF beta2 for the pathogenesis of the disease. Exp Eye Res 2005; 81: 1-4.

[21] CAT-152 Trabeculectomy Study Group. A phase III study of subconjunctival human anti transforming gtowth factor TGF- $\beta 2$ monoclonal antibody (CAT-152) to prevent scarring after first time trabeculectomy. Ophthalmology 2007; 114: 1822-30.

[22] Adachi S, Maruyama T, Kondo T, Todoroki T, Fukao K. The prevention of post operative intraperitoneal adhesions by tranilast: N-(3', 4'-dimethoxycinnamoyl) anthranilic acid. Surg Today 1999; 29: $51-4$.

[23] Howell JE, McAnulty RJ. TGF-beta: its role in asthma and therapeutic potential. Curr Drug Targets 2006; 7: 547-65.
[24] Lin Y, Nakachi K, Ito Y, Kikuchi S, Tamakoshi A, Yaqyu K, Watanabe $\mathrm{Y}$, Inaba $\mathrm{Y}$, Kazuo Tajima. Variations in serum transforming growth factor-beta 1 levels with gender, age and lifestyle factors of healthy Japanese adults. Dis Markers 2009; 27(1): 23-8.

[25] Tan C, Chew PT, Lum WL, Chee C. Trabeculectomy-success rates in a Singapore hospital. Singapore Med J 1996; 37(5); 505-7.

[26] Hooi ST, Hooi SH. Trabeculectomy outcomes in a Malaysian general hospital. Med J Malaysia 2003; 58(4): 565-78.

[27] Broadway DC, Grierson I, Hitchings R. Racial differencs in the results of glaucoma filtration surgery: are racial differences in the conjunctival cell profile important? Br J Ophtahlomol 1994; 78: 466-75.

[28] Khaw PT. Prolonged localized tissue effects from 5-minute exposure to fluorouracil and mitomycin C. Arch Ophthalmol 1993; 111: $263-7$.

(C) Ng et al.; Licensee Bentham Open.

This is an open access article licensed under the terms of the Creative Commons Attribution Non-Commercial License (http://creativecommons.org/licenses/by-nc/3.0/) which permits unrestricted, non-commercial use, distribution and reproduction in any medium, provided the work is properly cited. 